This is the preprint version of an article published in Argumentation 30 (4), 443-463. The final publication is available at Springer: https://link.springer.com/article/10.1007/s10503015-9389-8. Please cite the published version only.

\title{
How Morality Can Be Absent from Moral Arguments
}

What is a moral argument? A straightforward answer is that a moral argument is an argument dealing with moral issues, such as the permissibility of killing in certain circumstances. Let us call this the thin sense of 'moral argument'. Arguments that we find in normative and applied ethics are almost invariably moral in this sense. However, they often fail to be moral in other respects. In this article, I will discuss four ways in which morality can be absent from moral arguments in the thin sense. If these arguments suffer from an absence of morality in at least one of these ways, they are not moral arguments in, what I will call, the thick sense of 'moral argument'. ${ }^{1}$ A moral argument in the thick sense is an argument that could possibly qualify as a proper response to a moral problem, an argument of which we can imagine that it would help someone struggling with a real moral problem (as a problem in life rather than as a problem in philosophy) to cope with that problem. If an argument in moral philosophy is not thick, then we should not let it weigh upon our considerations of what we morally ought to do, even if we see no independent reason to question the truth of the premises or the logical validity of the argument. The absence of morality in thin arguments means that these arguments will fail to give us a reason to do whatever they claim that we ought to do. ${ }^{2}$

How can morality be absent from thin moral arguments? I will start, in the first section, with a few remarks made by Hans-Johann Glock about an argument of Peter Singer. I will argue that, if the conclusion of a moral argument involves or leads to the denial of a moral certainty, then the argument is not moral in the thick sense and could not qualify as a proper response to a moral problem. The idea of a moral certainty used in this section is based upon an extrapolation of Wittgenstein's ideas in On Certainty. In the second section, I will use the work of P. F. Strawson and Cora Diamond to support the claim that thin arguments often fail to recognize that a participant attitude is fundamental to morality. In the third section, drawing on remarks and distinctions by Stanley Cavell, Cora Diamond and Raimond Gaita, I will point out a problematic reduction in many thin arguments of moral thinking to thinking about what to do. The reduction is problematic when it obscures the fact that moral thinking aims at understanding the meaning of what we do. In the fourth section, I will show

\footnotetext{
${ }^{1}$ My distinction between 'thin' and 'thick' is related to, but different from the distinctions between 'thin' and 'thick' in Gilbert Ryle (2009, originally published in 1968), Clifford Geertz (1973), Bernard Williams (1985) and Michael Walzer (1994).

${ }^{2}$ I would like to thank an anonymous reviewer for the suggestion to put the point in these terms.
}

[Type here] 
This is the preprint version of an article published in Argumentation 30 (4), 443-463. The final publication is available at Springer: https://link.springer.com/article/10.1007/s10503015-9389-8. Please cite the published version only.

how the failure of certain thin arguments to take the personal character of moral problems into account disqualifies them as proper responses to these problems. In the fifth, and concluding, section, I will say something about how the distinction between thin and thick moral arguments invites a distinction between moral issues on one hand and moral problems on the other.

The aim of this article can be summarized by saying that I will offer a non-exhaustive overview of moral (as distinct from logical) reasons for not letting merely thin moral arguments weigh upon our considerations of what we morally ought to do. These reasons are not new. They are inspired by what I see as a Wittgensteinian tradition of moral philosophizing, since most of the authors discussed are heavily influenced by Wittgenstein. ${ }^{3}$ What is new in this article is that (1) these reasons (and their authors) are brought together in such a way that an overview of overlapping features emerges, that (2) they are explicitly characterized, within the framework of thin and thick moral arguments, as reasons for not letting thin moral arguments weigh upon our considerations of what we morally ought to do. (3) They are not identified as 'logical' reasons (available irrespective of one's moral outlook), but as moral ones, meaning that their availability is tied to a specific moral outlook, an understanding of morality and/or of the possibilities and limitations of moral philosophy. The article aims to make explicit what kind of understanding or outlook is required for these reasons to be available. (4) Certain relations between these reasons and certain distinctions 'within' them (such as the different ways in which a thin moral argument may fail to account for the personal character of moral problems) will become clearer.

\section{Denying a Moral Certainty}

In What Is Analytic Philosophy?, Hans-Johann Glock remarks that 'ever since Plato, philosophers have shown an uncanny willingness to follow the argument wherever it leads' (2008: 194). Glock explains what he finds uncanny:

Even on reaching absurd or repugnant conclusions, they [philosophers] have rarely engaged in soul-searching or questioned their own premises. Instead, they have

\footnotetext{
${ }^{3}$ I am speaking of a tradition in the sense explained by Glock, as 'held together both by ties of influence and by a family of partially overlapping features' (2008: 223). Glock distinguishes a tradition from a school, the latter being 'a tightly knit group based on relatively intimate personal contact and a direct transfer of certain doctrines of methods' (2008: 220).
}

[Type here] 
This is the preprint version of an article published in Argumentation 30 (4), 443-463. The final publication is available at Springer: https://link.springer.com/article/10.1007/s10503015-9389-8. Please cite the published version only.

devised clever arguments for dismissing the judgements, values and practices of ordinary mortals as unreflective and obsolete. (2008: 194)

Glock uses Singer's Practical Ethics as an example. In the first edition of his book, Singer, according to Glock,

[...] condones active non-voluntary euthanasia, the killing of innocent human beings that are incapable of understanding or making the choice between life and death - such as severely defective infants or grown-ups in a vegetative state. Moreover, he favours such a course of action not just in cases in which it is in the interest of the patient, but also in cases in which it is best for the patient's environment - the family or society. This includes both infants with Down's syndrome and haemophiliacs. (2008: 197) Singer's position, Glock maintains, is 'a showcase for a particular failure of rationality [...]: the failure to reconsider one's premises in the light of unpalatable consequences, and the tendency to seek refuge instead in self-serving animadversions against 'orthodox' or 'conventional' morality and 'lay' intuitions' (2008: 198).

Glock does not, I think, at least not at first, see Singer's argument as logically invalid or his conclusion as, logically speaking, inadequately supported. Rather, he seems to think that the conclusion cannot be the right one. He refuses to think about it as something that could possibly be right. Not only Singer's argument, but any argument (regardless of its 'argumentative' quality) that leads to such a conclusion must be dismissed, precisely because it leads to that conclusion. The possibility of a sound argument for non-voluntary euthanasia is excluded. But what gives Glock the right to do that?

Nobody will dispute that, whenever an argument the validity of which we have at first sight no reason to question leads to an unexpected or controversial conclusion that goes against received views or intuitions, there is good reason to question its premises. However, its being unexpected or controversial does not imply that the conclusion cannot be right or that the argument cannot be sound. If it implied that, then there would be no room for criticizing received views. So if we want to hold on to the idea that certain conclusions, such as Singer's, cannot be right, then there has to be something more to them than their just being unexpected or controversial. Glock thus invites us to distinguish between, on one hand, arguments and conclusions that we are willing to evaluate because they could possibly be right, however unexpected or controversial they may be, and, on the other hand, arguments and conclusions that we refuse to evaluate because they could not possibly be right. 
This is the preprint version of an article published in Argumentation 30 (4), 443-463. The final publication is available at Springer: https://link.springer.com/article/10.1007/s10503015-9389-8. Please cite the published version only.

It is helpful, in this regard, to have a look at Wittgenstein's On Certainty. Wittgenstein discusses statements such as 'I have a brain' (1975: §4), 'My body has never disappeared and reappeared after an interval' (1975: §101) and 'The earth has existed long before my birth' (1975: §84). These statements are more aptly characterized as certainties than as beliefs. In contrast to beliefs, they cannot be meaningfully doubted or challenged (1975: §234). Wittgenstein considers the case of someone who goes to the doctor, shows him his hand and says 'This is a hand'. He then asks: '[...] if it is open to doubt 'whether that is a hand', why isn't it also open to doubt whether I am a human being who is informing the doctor about this?' (1975: §460). These certainties belong to our 'frame of reference' (1975: §83), and to doubt them would be to 'knock from under my feet the ground on which I stand in making any judgments at all' (1975: §492). Certainties cannot be justified or denied because justifications or grounds for denying them will not be 'as certain as the very thing they were supposed to be grounds for' (1975: §307). Would we not refuse, asks Wittgenstein, 'to entertain any argument' that tried to show that the earth has existed for only a hundred years (1975: §577)? And would not such a refusal be reasonable? Here, 'we are not ready to let anything count as a disproof of this proposition' (1975: §245), and rightly so. Wittgenstein asks:

What if it seemed to turn out that what until now has seemed immune to doubt was a false assumption? Would I react as I do when a belief has proved to be false? [...] Would I simply say 'I should never have thought it!' - or would I (have to) refuse to revise my judgment - because such a 'revision' would amount to annihilation of all yardsticks? (1975: §492)

What Glock finds uncanny about the philosopher's willingness to follow the argument wherever it leads is, I presume, that this willingness testifies to an unwillingness to consider Wittgenstein's question as a legitimate one. That is, because of an 'exaggerated confidence in the power of philosophical judgment' (Glock 2008: 194), philosophers often fail to see that there is an alternative to the 'I should never have thought it!'-option.

Wittgenstein only discusses (what we could, roughly speaking, call) empirical certainties, but some commentators have argued that it is plausible to extrapolate his account to the moral realm and to speak of moral certainties as well. ${ }^{4}$ Nigel Pleasants, for instance, has convincingly argued that the wrongness of killing is such a certainty, and that it functioned as

\footnotetext{
${ }^{4}$ For a recent overview of the discussion and helpful references, see Pleasants 2015.
}

[Type here] 
This is the preprint version of an article published in Argumentation 30 (4), 443-463. The final publication is available at Springer: https://link.springer.com/article/10.1007/s10503015-9389-8. Please cite the published version only.

a certainty even for slaveholders and in the Third Reich (2008, 2015). It should be remembered that Glock describes Singer's argument as condoning 'the killing of innocent human beings' (my italics). Using Wittgenstein's conceptual tools, we could say that one of Glock's reasons for refusing to accept Singer's argument as an argument that could possibly be right is that it leads to the denial of a moral certainty. Glock understands 'it is wrong to kill innocent human beings' as relevantly analogous to 'the earth has existed long before my birth'. According to Wittgenstein, it is 'absurd' to doubt, justify or deny certainties (1975: $\S 460$ ), and it is conspicuous that Glock uses the very same term 'absurd' to characterize the conclusions of the philosophers that he challenges (2008: 194).

According to this proposal of forming an analogy between 'empirical' and moral certainties, 'it is wrong to kill innocent human beings' would be a statement that cannot be meaningfully doubted or challenged. Thus, it belongs to our frame of reference and to doubt it would be to knock from under our feet the ground on which we stand in making any moral judgments at all. Grounds for denying it will never be as certain as the very thing that they are supposed to be grounds for and we are not ready to let anything count as a disproof of this proposition.

Although the analogy between empirical and moral certainties may seem attractive at first sight, there is what can be called a problem of criticism. The distinction between beliefs and certainties saves the possibility of criticizing received beliefs, but it raises questions about the possibility of doubting or criticizing certainties. Wittgenstein's point is not that all certainties have remained the same throughout history and that they stand forever. It is not impossible that, in certain circumstances, what was immune to doubt at one point becomes open to doubt at another; what was certainty becomes belief and the other way round:

The mythology may change back into a state of flux, the river-bed of thoughts may shift. But I distinguish between the movement of the waters on the river-bed and the shift of the bed itself; though there is not a sharp division of the one from the other. (1975: §97)

One could think here, I suppose, of the way in which Galilei made it possible to criticize what until then had functioned as a certainty, namely the certainty that the sun revolves around the earth. That certainty became a criticisable belief, the belief was shown to be false and it was replaced by the belief that the earth revolves around the sun, a belief which has now become a new certainty.

[Type here] 
This is the preprint version of an article published in Argumentation 30 (4), 443-463. The final publication is available at Springer: https://link.springer.com/article/10.1007/s10503015-9389-8. Please cite the published version only.

The question now is as follows: could we not regard Singer as someone who does for morality what Galilei did for astronomy, that is, as someone who makes it possible to criticize what many regard as immune to doubt? If the consequence of such criticism is that the whole frame of reference changes, then why should we bother about that? What matters is not whether the frame of reference changes or not, but whether it is the right frame of reference. If Galilei was right, it seems that Singer could be right as well.

Or not? Those who maintain, with Glock, that Singer's conclusion cannot be right, have resources to respond to this challenge. They could argue that moral certainties are different from at least some empirical certainties when it comes to the possibility of radical change. After all, Wittgenstein does not hold that all certainties are open to change:

And the bank of that river consists partly of hard rock, subject to no alteration or only to an imperceptible one, partly of sand, which now in one place now in another gets washed away, or deposited. (1975: §99)

The question then is why moral certainties would be 'hard rock' (or more likely to be hard rock than empirical ones), while at least some empirical certainties are not. Sabina Lovibond suggests an answer (or the direction to an answer) to that question when she says that, in moral matters, we do not have the idea of fresh evidence, an idea that 'belongs to' our concept of the physical world, but not to our (possible) concept of the moral world' (1983: 7980). Although I suppose that fresh evidence could not possibly influence the hard rock certainty that this is my hand, for example, it has justified scientific revolutions and revolutions in our conception of the physical world. Similar revolutionary changes in our conception of the moral world would then be unjustifiable, because there is no such thing as fresh evidence or new discoveries here. Peter Hacker makes a related point about evidence and discoveries in relation to philosophy. If we give it a moral twist, it would go as follows: 'The characteristic reaction to an advance in scientific knowledge is 'Goodness me, who would have thought of that!', whereas the characteristic response to a moral [Hacker has 'philosophical'] insight is 'Of course, I should have thought of that!' (2009: 148). Hacker thus suggests that the 'I should never have thought it!'-reaction is not open to us in morality. The moral philosopher's task would thereby not be to revise or revolutionize, but rather to make us understand. Moral exemplars such as Gandhi and Nelson Mandela did not come up with new evidence or revolutionize our conception of what is morally advisable or 
This is the preprint version of an article published in Argumentation 30 (4), 443-463. The final publication is available at Springer: https://link.springer.com/article/10.1007/s10503015-9389-8. Please cite the published version only.

permissible. Rather, they deepened or reminded us in a powerful way of what, in a sense, we already knew. As Raimond Gaita formulates it,

Ethical understanding is often coming to see sense where we had not seen it before, or coming to see depth where we had not seen it before. It is seldom learning something completely new (there are no Nobel Prize-winning discoveries in ethics) and it is seldom seeing that there is, after all, a valid argument to support positions we had previously judged to be dubious. It is often seeing what someone has made of something that we had often heard before. (2004: 281)

The line of response suggested by Lovibond, Hacker and Gaita does not lead to a conventionalist position and is not meant to prove that, in moral matters, no such thing as a revolution is possible. If we understand a moral revolution to be a radical change in our ways of dealing with and thinking about moral matters, then, for example, the fact that we no longer regard slavery as morally permissible shows that there has been a moral revolution. But in contrast to scientific revolutions, such a revolution is typically not the result of new discoveries or fresh evidence. Moreover, some proposed way of acting or thinking will only count as a candidate for a possible moral revolution if it somehow succeeds in showing that our moral certainties lead us into (or at least do not conflict with) acting or thinking in such ways, while something, if it is supported by evidence, might be a candidate for an empirical revolution even when it goes against empirical certainties (see the Galilei example). If a proposed way of acting or thinking is understood to go against the moral certainty that killing innocent people is wrong, for example, then we will typically not consider it to be a good candidate for a moral revolution, and rightly so. This is why Glock dismisses Singer's argument. If, on the other hand, a radically new proposed way of acting or thinking can be shown to be implied or suggested by our moral certainties, its prospects are much better. Take, for example, the idea that killing animals is wrong. The certainty that killing people is wrong, in combination with the belief that animals are relevantly similar to people (engendered, for example, by Frans de Waal's (2006) observations regarding the competences of certain animals), may very well lead one to think that it is wrong to kill animals. Such a belief seems like a good candidate for a moral revolution, precisely because it does not conflict with our moral certainties. Singer's critique of speciesism (2009) is therefore much more likely to spark a moral revolution than his argument in favour of non-voluntary 
This is the preprint version of an article published in Argumentation 30 (4), 443-463. The final publication is available at Springer: https://link.springer.com/article/10.1007/s10503015-9389-8. Please cite the published version only.

euthanasia (at least if we understand the latter as Glock understands it, namely as condoning the killing of innocent human beings).

If a moral revolution is understood as a radical change in our dealing with and thinking about moral matters, then the idea of moral certainty does not exclude moral revolutions. If, however, a moral revolution is taken to be a change so radical that, for example, 'killing innocent people is wrong' would no longer be a certainty, then it is doubtful as to whether we can conceive of anything like a moral revolution at all. If people were to start randomly killing each other, then they have not so much radically changed their moral system or their morality. They should rather be said to have left the moral sphere completely. It would be hopelessly inadequate to call what these people are doing 'morally wrong', 'cruel' or 'immoral', that is, to condemn it in everyday moral terms. Rather, we would say that they do not know what morality is or is about. Their revolution is not a revolution from one moral way of thinking to another, it is a revolution from morality to something else, and it is at least doubtful whether we would still be able to see these people as living a human form of life (see, on this point, Rummens 2013: 146). ${ }^{5}$

Lovibond's and Gaita's remarks about morality and moral philosophy do not exclude moral revolutions. Rather, they show that those who maintain that Singer's conclusion cannot be right (because it involves or leads to the denial of a moral certainty) have resources to respond to those who (claim to) see no crucial difference between criticizing certain empirical certainties, such as the certainty that the sun revolves around the earth, and criticizing moral ones, such as the certainty that killing innocent people is wrong. It is morally and philosophically defensible to say that the conclusion of a moral argument cannot be right because it involves or leads to the denial of a moral certainty. By 'philosophically defensible', I mean that it does not suffice to assert, dogmatically, that a certain conclusion denies a moral

\footnotetext{
${ }^{5}$ A reviewer has remarked that it is not really clear where to draw the line between moral change or evolution and moral revolution. I cannot deal with the issue at length here, but I can say, first, that an answer to this remark crucially depends on one's understanding of 'moral revolution'. If a moral revolution is a change so radical that our moral certainties such as 'killing innocent people is wrong' would no longer be certainties, then it is doubtful, as I have tried to make clear, whether we can conceive of anything like a moral revolution at all. If, on the other hand, a moral revolution is a radical change in our dealing with and thinking about moral matters, then there can be moral revolutions, but whether something is a revolution or an evolution will then depend on how radical the change is. I would say that the way in which we think about slavery has undergone a revolution rather than an evolution, while the way in which we treat animals has undergone an evolution but not (yet?) a revolution. Admittedly, the distinction is not clear-cut, and neither is the distinction between 'radical' and 'not radical'. The fact that there is a grey zone here does not prove, in my view, that the distinction is useless, and I do not even know whether we should try to draw a clear line between evolutions and revolutions. See, on a related point, footnote 14 .
}

[Type here] 
This is the preprint version of an article published in Argumentation 30 (4), 443-463. The final publication is available at Springer: https://link.springer.com/article/10.1007/s10503015-9389-8. Please cite the published version only.

certainty and should therefore be dismissed (as it does not suffice to assert, dogmatically, that everything is open to doubt). There are criteria for what counts as a certainty and those who defend that something is a moral certainty have to show that it fulfills these criteria. ${ }^{6}$ Moreover, they will be committed to subscribe to a certain understanding of morality and moral philosophy (see Lovibond's and Gaita's understanding of morality and moral philosophy). I conclude that, if a thin moral argument involves or leads to the denial of a moral certainty, and given a certain understanding of morality and moral philosophy, there is good reason to regard that thin argument as one that we should not take into consideration when deliberating about what we morally ought to do.

\section{No 'Attitude Towards a Soul'}

Another (but obviously related) reason for refusing to accept a moral argument as one that could possibly qualify as a proper response to a moral problem is the absence of a moral attitude in the way that the argument deals with the issue. Cavell discerns this kind of 'absence of morality' in Stevenson's Ethics and Language (1979: 274-291). Cavell finds fault, in particular, with Stevenson's saying that 'Any statement about any matter of fact which any speaker considers likely to alter attitudes may be adduced as a reason for or against an ethical judgment' (1979: 274). According to Cavell, Stevenson commits a sort of category mistake and is unable to recognize that some reasons can be of the wrong kind. ${ }^{7}$ Cavell accuses Stevenson of not seeing that some kinds of reasons do not have a place in thick moral arguments, even if a speaker considers them likely to alter attitudes. If we look back at Glock's description and dismissal of Singer's argument and conclusion, precisely this idea of reasons being of the wrong kind seems to play a major role. One of the reasons Singer invokes, according to Glock, for condoning the killing of certain human beings is that it is sometimes best for their environment. The problem with this reason is not so much that it does not support (or inadequately supports) the conclusion, but that it is the wrong kind of reason. Why?

\footnotetext{
${ }^{6}$ A good overview of the characteristics of certainties can be found in Rummens (2013). For reasons of space, I can only briefly mention them here. (1) Basic certainties cannot be meaningfully doubted. (2) Basic certainties cannot be justified. (3) Basic certainties are certainties of our acting. (4) Doubt regarding basic certainties is a form of insanity. (5) Basic certainties are the preconditions of local doubt. (6) Basic certainties form a system. (7) Basic certainties are not necessarily certain (they are not conceptual or a priori truths) (2013: 134).

${ }^{7}$ I would like to thank an anonymous reviewer for the suggestion to put the point in these terms.
} 
This is the preprint version of an article published in Argumentation 30 (4), 443-463. The final publication is available at Springer: https://link.springer.com/article/10.1007/s10503015-9389-8. Please cite the published version only.

Singer's reason, it could be said, testifies to what P. F. Strawson has called an 'objective attitude' (2009: 155) towards other human beings. Such an attitude sees them as subjects for treatment or objects of social policy, as something 'to be managed or handled or cured or trained' (2009: 155). An objective attitude 'cannot include the range of [...] attitudes which belong to involvement or participation with others in inter-personal relationships' (2009: 156). The objective attitude is opposed in Strawson's paper to a participant attitude, and I understand such a participant attitude to be relevantly similar to what Wittgenstein has called 'an attitude towards a soul' (2009b: §22).

The idea that a moral argument should embody a participant attitude in order to qualify as thick may be understood in three different ways, depending on the answer to the question 'a participant attitude towards whom?' The first way to answer this question is by saying that a thick argument should involve a participant attitude towards the persons that we are arguing about. Suppose that Sophie tries to convince John that he should bring his mother to a retirement home. Sophie's argument could only qualify as a proper response to John's moral problem if it embodies a participant attitude towards John's mother. The second way to answer the question is by saying that a thick argument should involve a participant attitude towards the persons we are arguing with. So in the case of Sophie and John, Sophie's argument could only qualify as a proper response to John's moral problem if it embodies a participant attitude towards him. The third answer is that, in order for a moral argument to be thick, it should involve a participant attitude towards both those about whom we are arguing and those with whom we are arguing, and this is the way in which I propose to understand the idea that a thick moral argument should embody a participant attitude or an attitude towards a soul. ${ }^{8}$ If such an attitude is lacking in a moral argument, we have good reason not to let it weigh on our deliberations about what we morally ought to do. The thin argument fails to give us a reason to do whatever it claims that we ought to do because it misses something that we regard as essential to morality and thus fails, in a thick sense, to be a moral argument at all. If

\footnotetext{
${ }^{8}$ In an earlier version of this article, I maintained that a thick moral argument should embody what Lawrence Blum has called 'a sense of shared humanity, of regarding the other as a fellow human being' (1994: 177). Reviewers have remarked that this formulation raises questions about whether we should restrict the moral community to humans alone. I believe that 'a participant attitude' and 'an attitude towards a soul' are better ways of making the point, since these formulations do not exclude that we can take up these attitudes towards animals as well. This is not to say that we only have moral responsibilities towards other human beings and animals, and not, for example, towards the environment. The need for a participant attitude will boil down, in these cases, to the need for a participant attitude towards those we are arguing with, an attitude that shows awareness of our shared responsibility towards the environment.
}

[Type here] 
This is the preprint version of an article published in Argumentation 30 (4), 443-463. The final publication is available at Springer: https://link.springer.com/article/10.1007/s10503015-9389-8. Please cite the published version only.

what purports to be a response to a moral problem reflects a misunderstanding of morality, then why should we bother about what it says we morally ought to do?

Is it not dogmatic to argue that 'This argument fails to display a moral attitude, therefore it cannot be accepted'? As dogmatic, I would say, as 'This is a moral certainty, so it cannot be meaningfully denied'. That is, it does not suffice to assert that an argument does not embody a moral attitude. A characterization of that attitude and an explanation as to why one takes this attitude to be characteristic of or essential to morality are required. Again, the availability of reasons like 'this argument is not moral at all' (in the thick sense) or 'these are reasons of the wrong kind', will crucially depend upon one's own conception of morality. That is not, however, a weakness: everyone operates with $a$ conception of morality. It seems much more dubious to claim that these reasons are available independently of one's conception of morality, for that would make them morally neutral, while those who invoke them want them to reflect a moral outlook. They do not reject the argument on logical grounds (available irrespective of one's understanding of morality or moral outlook), but on moral grounds.

I have focused on the absence of a participant attitude in moral arguments. Yet such an absence often occurs much 'earlier', namely, in the formulation or presentation of the problem. In 'What if $\mathrm{x}$ isn't the number of sheep? Wittgenstein and Thought-Experiments in Ethics' (2002), Cora Diamond refers to a discussion by Carol Gilligan of a hypothetical case in which a man must decide whether or not to steal the drug necessary to save his wife's life. When confronted with the dilemma, a girl said that communication should be re-opened with the druggist, although it had been stipulated that no further communication was possible. One could respond here, as Roy Sorensen did, that the girl's response is misconceived because the man's situation 'isn't being reported [...], it is being stipulated' (2002: 238). Hence, according to Sorensen, 'it's no more open to say in response that communication should be re-opened with the druggist than it is to respond to the mathematical stipulation 'Let $\mathrm{x}$ be the number of sheep' as did the schoolboy in the story, 'But, Sir, what if $\mathrm{x}$ isn't the number of sheep?" (2002: 238). The problem with this response, Diamond says, is that 'in moral life we are not in general confronted with cases the description of which can be taken to be simply 'given' (2002: 238). The girl's answer is one that rejects the presentation of the problem because that presentation already leaves out a the possibility of a participant attitude: it does not represent the druggist as a fellow human being, a being that could be responsive to our 
This is the preprint version of an article published in Argumentation 30 (4), 443-463. The final publication is available at Springer: https://link.springer.com/article/10.1007/s10503015-9389-8. Please cite the published version only.

reasons or pleas for re-opening communication. Hence, the presentation of the problem already precludes what would be a moral course of action. According to Diamond, the girl has good moral reason to answer as she does.

Diamond's general point is that, in moral matters, 'describing the situation is frequently itself part of the problem' (2002: 239). The point is illustrated by Elizabeth Anscombe's reaction to the use of hypothetical dilemmas by consequentialists 'who ask whether it would not be right to execute an innocent person if that were the only way to avert a nuclear war' (2002: 239). According to Anscombe, 'the most important thing about the way such cases are invented in discussions is the assumption that only two courses are open' (2002: 239). Diamond explains:

[...] it's no part of Anscombe's view of moral thought or moral theorizing that we should be able to say what it would be good to do in every stipulatable set of circumstances. ${ }^{9}$ Her kind of moral thinking (and other kinds of moral thinking as well) rejects the invitation to resolve in advance, on the stipulated terms, horrific hypothetical dilemmas. One might hope to have, if one ever were in such horrific circumstances, the capacity to re-conceive the situation, to see possibilities at first unsuspected. [...] He [Sorensen] obviously thinks Anscombe's suggestion about the nuclear war dilemma is simply an attempt to avoid the fact that thought-experiments like that one have embarrassing consequences for her kind of approach to ethics. But her view is rather that they have no consequences at all; they are simply part of a consequentialist conception of what a moral theory should do, and of what moral life is like. (239-240)

Similar considerations are voiced by Gaita, who discusses the example of a person presented a with similar dilemma (2004: 64-73). If he kills one innocent person, ten others will be saved. If he does not, they will all be killed. To present the matter in this way, Gaita claims, is to simplify the man's sense of what he might be doing. 'It is already to see the situation in the morally flat light of consequentialist theory' (2004: 71), a light, we can say, that prevents us from responding to the situation in a way that reflects an attitude towards a soul.

In short, if a thin moral argument presents a moral problem in a way that involves no participant attitude, or if the argument, the reasons provided for the conclusion or the conclusion itself, suffer from such an absence of morality, then that is a reason not to think of

\footnotetext{
${ }^{9}$ According to Gaita, 'it is mere prejudice to believe that it is an obvious virtue of a philosophical account of ethics to characterise our sense of the ethical in such a way as to yield a decision procedure for what to do in any conceivable situation' (2004: 73).
}

[Type here] 
This is the preprint version of an article published in Argumentation 30 (4), 443-463. The final publication is available at Springer: https://link.springer.com/article/10.1007/s10503015-9389-8. Please cite the published version only.

the argument as moral in the thick sense, given a certain conception of morality. Slightly adapting a phrase from Wittgenstein's 'Lecture on Ethics', we could say that 'When we look at it in this way, everything moral has disappeared' (2014: 50).

\section{No Deepened Understanding}

How can a thin moral argument fail to be thick? In this section, using distinctions by Cavell and Diamond, I will argue that thin arguments often present moral problems as well-posed problems, while it may be more appropriate to treat them as exploration problems.

Consider, first, the following dialogue, an example that runs through Cavell's The Claim of Reason:
A There is a goldfinch in the garden.
B How do you know?
A It has a red head.
B But goldcrests also have red heads.

B has opened ground for doubt and thereby reveals that A's claim about the goldfinch has been insufficiently supported. According to Cavell,

[...] if the argument is to continue then either the ground for doubt must itself be impugned ('The shape of a goldcrest's head is different') or a new basis proposed ('I know not just from the head, but from the eye-markings'), and every person competent to enter claims to knowledge knows the significance of this. We could say: It is not up to the protagonists to assign their own significance to bases and grounds for doubt; what will count as an adequate basis and sufficient ground for doubt is determined by the setting of the assessment itself. When I counter a basis by saying 'But that's not enough', there is no room for you to say, 'For me it is enough'. (1979: 267)

Cavell compares the goldfinch example to several moral cases. I propose to compare it to a new example:
A Barry is an untrustworthy person.
B Why do you believe that?
A He promised to talk about our problems yesterday evening, but he didn't turn up. He didn't even send a message and he didn't pick up the phone.
B But his mother fell ill two days ago. He is often with her, she counts on him. 
This is the preprint version of an article published in Argumentation 30 (4), 443-463. The final publication is available at Springer: https://link.springer.com/article/10.1007/s10503015-9389-8. Please cite the published version only.

As in the goldfinch example, the ground for doubt can be impugned ('I called his mother to ask if he was there. He was not.') or a new basis can be proposed ('It's not just about what happened yesterday. Last month, for example, he ...'). In contrast to the goldfinch example, however, there is room for A to refuse to accept B's ground for doubt, 'without impugning it as false, and without supplying a new basis, and yet not automatically be dismissed as irrational or morally incompetent' (1979: 267). Although A, if she is morally competent, will not fail to see that B's consideration requires a determination by her, it is up to her to determine whether what B says is enough to counter her claim to be right or justified in saying that Barry is untrustworthy. A could say, for example, 'That does not make him more trustworthy', and it could be reasonable for her to say so. In the goldfinch example, by contrast, 'the relevance of the doubt is itself enough to impugn the basis as it stands' (1979: 267).

What Cavell's distinction between the goldfinch example and moral cases tells us about moral arguments is, I take it, that what will count as an adequate basis or sufficient ground for doubt is often unclear and even in question in moral arguments, while it is often treated as given or taken for granted in other kinds of argument. Something similar holds for the meaning of moral concepts. While the meaning of a concept is often treated as given in arguments, in moral arguments this meaning is often unclear or in question (Murdoch 2001: 27). That does not mean that moral arguments are explicitly about sufficient bases, grounds for doubt or the meaning of moral concepts (they sometimes are, of course). Instead, it means that questioning these bases, grounds and meanings is a legitimate move within moral disputes, even if they are not explicitly concerned with bases, grounds and meanings. There is room, within moral arguments, to question bases, grounds and meanings, and this room characterizes moral arguments (which is not to say that it cannot be characteristic of other kinds of argument, such as arguments in aesthetics or arguments in science). If, for example, in response to a question about whether a given person ought to be punished, one simply refers to the rules of an institution (and thereby refuses to acknowledge that, within a moral argument, there is room to question these rules), then that is, according to Cavell, 'to refuse to allow a moral question to be raised' (1979: 303). ${ }^{10}$

\footnotetext{
${ }^{10}$ Compare Murdoch: '[...] it is characteristic of morals that one cannot rest entirely at the conventional level, and that in some ways one ought not to' (2001: 29).
}

[Type here] 
This is the preprint version of an article published in Argumentation 30 (4), 443-463. The final publication is available at Springer: https://link.springer.com/article/10.1007/s10503015-9389-8. Please cite the published version only.

A similar point has been made by Wittgenstein in a discussion recorded by Rush Rhees. Rhees presents Wittgenstein with the example of a man who has come to the conclusion that he must either leave his wife or abandon his work of cancer research. Wittgenstein says that 'here, we may say that we have all the materials of a tragedy' if we are talking about a man 'who does not have an ethics' (1965: 23). But if he does have an ethics, his problem is different. If he is a Christian, for example, 'he has got to stick to her come what may. [...] The question 'Should I leave her or not?' is not a problem here' (1965: 23). So, a question or problem that can be solved (that one accepts to solve or treat) within a system of rules or by reference to an institution in which it is clear what adequate bases and sufficient ground for doubts are and what concepts mean, is different from a question or problem that cannot be so solved (that one refuses to so solve or treat), a question or problem that invites exploration of and discussion about these meanings, bases and grounds. I will follow Diamond in calling the former kind of problems 'well-posed problems' and the latter 'exploration problems' (2002: 241-242), although my distinction may be slightly different from hers.

We have seen that, if we call an argument 'moral' in virtue of the fact that it concerns moral issues (the permissibility of killing, for example), it can fail to be moral in the thick sense if it does not embody a participant attitude. In section two, we considered a question to be rightfully treated as well-posed, but the bases and grounds for doubt one invokes, and sometimes also the description of the problem, and the attitude towards the problem these reflect, are not those of (do not fit in) a moral (in the thick sense) system or institution. As the Cavell-Wittgenstein-Diamond distinction shows, a thin argument can also fail to be moral in the sense that it treats as well-posed a problem or question that is not obviously to be taken as well-posed (that could competently be taken as an exploration problem). If it does so, I argue, the thin argument will fail to give us reason to do whatever it claims that we ought to do.

Take Wittgenstein's example of the man who has come to the conclusion that he must either leave his wife or abandon his work of cancer research. Suppose that this man, Billy, turns to his best friend Lynn for help and presents her with the dilemma. She answers his request by offering him a moral argument. She sets out the premises and starts reasoning. Billy has no reason to think that her conclusion will involve the denial of a moral certainty, and the way she argues clearly testifies of a participant attitude. Lynn tries to help Billy to reconceive the situation, to see possibilities at first unsuspected, and so on. Yet something 
This is the preprint version of an article published in Argumentation 30 (4), 443-463. The final publication is available at Springer: https://link.springer.com/article/10.1007/s10503015-9389-8. Please cite the published version only.

disturbs him: she obviously intends to reach a conclusion and tell him what would be best for him to do. She treats his problem as if it were well-posed, his question as if it were asking for a solution of the form 'You ought to do x'. And that may be something Billy does not want and, independently of what Lynn's conclusion will be, something he can reasonably refuse to accept, because he sees his problem as an exploration problem or at least as having an ineliminable and central exploration aspect. The point is not that he is not trying to find out what he should do (he clearly is), but that, even if he asked her explicitly what he should do, he may only want her to help him make a decision (see, on this point, Rhees 1999: 69). He may think or feel that it is not up to her to determine whether the reasons she invokes for or against a certain way of acting are 'enough'. Lynn's response comes too close to a decision. It leaves no room for discussion about meanings, adequate bases and grounds for doubt, a kind of discussion that he may take his moral problem to have invited. It is closed in a way that moral arguments should not be. It is concerned exclusively with what Billy should do, whereas, as Gaita has insightfully remarked,

[...] much moral thinking is not thinking what to do, and even when it is it is also an attempt to understand the meaning of what we do, which is rarely thinking about the empirical consequences of what we do, or about how our principles stand in relation to those consequences and to one another. It is, most often, an attempt to achieve a deepened understanding of the meaning of our actions. That, as much as conscientiousness, is a mark of moral seriousness and of what we should understand by having arrived at a 'right answer' to a moral question. (2004: 264)

Billy is likely to think that he cannot and should not take or accept a decision, that he cannot and should not answer or accept an answer to his question unless he understands as adequately and deeply as possible the meaning of his problem and of the alternative courses of action open to him. If Lynn's argument does not offer such an understanding, because it reduces moral thinking to thinking about what to do (ignoring the exploration part of his problem, taking for granted that what it presents as the meaning of certain moral concepts and as sufficient bases and grounds for doubt are not in dispute), it will fail to give Billy reason to do whatever it concludes that he ought to do. The problem is not that Lynn's answer is or cannot be the right one (as in section one), or that it lacks a participant attitude (as in section two), but that it is not an answer to his question or a solution to his problem. It misjudges the kind of problem that he has.

[Type here] 
This is the preprint version of an article published in Argumentation 30 (4), 443-463. The final publication is available at Springer: https://link.springer.com/article/10.1007/s10503015-9389-8. Please cite the published version only.

\section{Ignoring the Personal}

It is often said that moral problems are personal. ${ }^{11} \mathrm{I}$ will argue that, if a thin moral argument ignores the personal character of the problem that it purports to deal with, we should not let it weigh upon our considerations of what we morally ought to do. The question then is as follows: in what sense are moral problems rightfully thought to be personal, and how can thin moral arguments fail to capture this? I will distinguish between three ways in which a thin moral argument's failing to be personal gives us a reason to reject it as a proper response to a moral problem.

Firstly, what people ought to do may reasonably be thought to depend upon what they are capable of doing (if 'ought' implies 'can'), on what their responsibilities are, what their history is, etc., in short, on their personal characteristics. According to Rhees, personal characteristics determine not only what someone ought to do, but also what her moral problem is. Reasons may weigh differently from one person to another, 'and what makes it the problem it is for me are the reasons which weigh with me in the one direction and in the other' (1999: 50). If the weight of reasons makes a moral problem the kind of problem that it is (Billy's problem would not be the same problem, or not even a problem, if his reasons would not weigh with him as they do), and if different people weigh moral reasons differently and are justified in doing so (as the difference between the goldfinch case and Barry's case and Cavell's comments upon such cases suggest), then another person cannot solve my moral problem in the sense that an ornithologist can solve my goldfinch problem. This raises wellknown difficulties for issues of moral advice, moral expertise and moral deference. I have discussed these issues elsewhere and will not pursue them further here. What is important for our purposes is that these problems go together with questions about the teachability of ethics and the possibility (and desirability) of action-guiding moral theory. While some just note that the individual or personal character of moral problems and their solutions makes it 'difficult to learn goodness from another person' (Murdoch 2001: 29), others argue that it makes teaching ethics impossible.

Such an outright dismissal of ethical theory and of the teachability of ethics may seem exaggerated. Even if moral problems are personal in the sense that reasons weigh differently

\footnotetext{
${ }^{11}$ Note that I do not say 'subjective'. The pairs personal-impersonal and subjective-objective are not equivalent, for the personal may be objective. While many philosophers will be inclined to say that morality is personal in some sense or another, not so many hold that it is subjective.
}

[Type here] 
This is the preprint version of an article published in Argumentation 30 (4), 443-463. The final publication is available at Springer: https://link.springer.com/article/10.1007/s10503015-9389-8. Please cite the published version only.

with different persons, it may be argued that this does not harm the teachability of ethics. And even if the personal character of moral problems makes it misleading to talk of moral theories, it does not necessarily lead to problems for action-guiding moral arguments. The reason is that such arguments can take all relevant personal characteristics (among which the way reasons weigh with this or that person) into account. The question then simply changes from 'What ought to be done in this situation?' to 'What ought this person to do in this situation?' Billy, for example, can inform Lynn about how reasons weigh with him, and she can take this information into account when offering him a moral argument. Moral arguments, it seems, do not necessarily have difficulties with the personal character of moral problems.

Or do they? It should be noted that 'taking personal characteristics into account' is easier said than done. Billy can be mistaken or unsure (which seems rather common) about how reasons weigh with him, and Lynn will have to know him very well in order to judge that. If a person's unique history is often important for determining what he ought to do, then taking relevant personal characteristics into account will amount to taking 'the details of this personality' (Murdoch 2001: 22) into account. Generally speaking, we can say that the more that a moral argument succeeds in taking someone's unique personality into account, the more restricted the scope of the argument will be: it will, ultimately, only tell one man what he ought to do in a specific situation. If that is what moral arguments (should) do, relevant instances will be found in literature and in people's personal lives rather than in moral philosophy. If, on the other hand, the argument is less personal, its scope will be broader. It will apply to what philosophers, attempting to steer a middle course between extreme particularism and crude, impersonal generalism all too easily refer to as 'similar persons in similar circumstances', as if there were no crucial question about what 'similar' means here. ${ }^{12}$ At the same time, the argument's conclusion will be more likely to be misleading: it may no longer be a solution to this person's problem, so why should he let it weigh upon his deliberations of what he morally ought to do?

Even if we restrict the scope of moral arguments and understand them in an extremely particularistic way, as unique arguments for unique persons, there is a second sense in which

\footnotetext{
${ }^{12}$ Murdoch remarks: 'It is all very well to say that 'to copy a right action is to act rightly' (Hampshire, Logic and Appreciation), but what is the form which I am supposed to copy? It is a truism of recent philosophy that this operation of discerning the form is fairly easy [...]' (2001: 29). Against 'similar persons in similar circumstances' arguments, see Gaita 2004: 67 and Rhees 1999: 50.
}

[Type here] 
This is the preprint version of an article published in Argumentation 30 (4), 443-463. The final publication is available at Springer: https://link.springer.com/article/10.1007/s10503015-9389-8. Please cite the published version only.

thin arguments may fail to be personal, a sense that was already implicit in the previous section. An example from Gaita will help to make it more explicit:

If I am deliberating about which is the best route off the mountain and I fail to arrive at an answer, I can pass the problem over to my partner. It is only accidentally my problem. If I am deliberating about what morally to do, then I cannot pass my problem over to anyone else. It is non-accidentally and inescapably mine. [...] If I seek your advice on which is the best route off the mountain, then the nature of what I do in asking for it, and what you do in giving it, is conditioned by the fact that I may hand the problem over to you completely (perhaps you are better at it, or perhaps I have lost my nerve), by the fact that I may consult manuals and by other such familiar facts. But if I must make a moral decision by Monday, I cannot come to you on Friday evening, plead that I have little time over the weekend to think about it, and ask you, a rational and informed agent and a professor of ethics to boot, to try to have a solution, or at least a range of options, no later than first thing on Monday morning. (2004: 103)

Why are moral problems 'non-accidentally and inescapably mine'? It is not just because nobody happens to know me better than I know myself, because nobody is capable of taking my personal characteristics into account in a way and up to a degree that would be satisfactory. The problem here is not that others happen not to be able to do something for me, as if something were empirically implausible or impossible. It lies deeper and is more fundamental: I ought to think the problem through for myself. With moral problems comes the moral task to think about them. If Billy were to consult the smartest professor of ethics in the world and unthinkingly take whatever advice she gives, we would rightfully think that he has missed something about the kind of problem that he is dealing with. It is up to him to determine whether the reasons invoked by the professor (or the wise person, or whoever advises him) are 'enough'. Not because nobody else is capable of doing it for him, but simply because he ought to do it, and because it would be irresponsible and careless not to do it. ${ }^{13}$ If, upon hearing that Billy was planning to consult a professor of ethics about his problem and to take her advice, whatever it may be, his wife was to feel scandalized or indignant, we would understand her. But if he doubts about whether the bird in his garden is a goldfinch or a goldcrest, and if in order to make really sure he would consult the smartest ornithologist in the world, he would, in normal circumstances, be justified in believing the ornithologist, and there

\footnotetext{
${ }^{13}$ Compare Murdoch's description of someone's moral activity as 'peculiarly her own' (2001: 22).
}

[Type here] 
This is the preprint version of an article published in Argumentation 30 (4), 443-463. The final publication is available at Springer: https://link.springer.com/article/10.1007/s10503015-9389-8. Please cite the published version only.

would be no reason for his wife to be scandalized or indignant about it. Problems about moral advice and deference, the teachability of ethics and the possibility of action-guiding moral theory resurface here. It is this second sense of 'personal' that Wittgenstein, for example, emphasizes when he says that 'an ethical proposition is a personal act' (1999: 43), and it is the 'non-accidentally and inescapably mine' of moral problems that prompts him to say, in a conversation with members of the Vienna Circle:

If I were told anything that was a theory, I would say, No, no! That does not interest me. Even if this theory were true, it would not interest me - it would not be the exact thing I was looking for.

What is ethical cannot be taught. (McGuinness 1979: 116-117)

If moral problems are personal in the sense just outlined, if dealing with them has an irreducibly personal aspect, then moral arguments, even if put forward by experts, will often fail to give us reason to do whatever they conclude that we ought to do. Not because these arguments are likely to be invalid or because the conclusions are likely to be wrong, but because they conclude that we ought to do so and so. The problem is that the argument may come too close to a decision, like arguments that treat exploration problems as well-posed problems often do. It leaves no room for the personal task that Billy ought to accomplish. It ignores his responsibility in a way that both he and his wife may think unwelcome. ${ }^{14}$

A third sense in which moral arguments can fail to capture the personal element of moral problems concerns the person offering the argument rather than the person for whom it is meant (as in the first and second sense). This can be discerned in what Gaita says about moral advice. According to Gaita, 'we would not seek moral advice from someone whom we knew to be morally jaded', while 'being scientifically jaded [...] is of itself no bar to a scientist's authority to speak in his field' (2004: 268).

The difference has to do with what it is to have 'something to say' in each of these cases. We say of some people that they 'have something to say' on moral or spiritual matters, but we do not mean that they have information to impart or a theory to propound. We mean that they speak with an individual voice, but not because they know something that few people know. (2004: 268)

\footnotetext{
${ }^{14}$ The boundary between offering guidance and telling us what to do is blurred, and different persons confronted with the same argument may reasonably locate it on different sides of the boundary.
}

[Type here] 
This is the preprint version of an article published in Argumentation 30 (4), 443-463. The final publication is available at Springer: https://link.springer.com/article/10.1007/s10503015-9389-8. Please cite the published version only.

In moral matters, Gaita continues, 'to have something to say is to be 'present' in what we say and to those to whom we are speaking', and 'what is said is not extractable from the manner of its disclosure' (2004: 268). The conclusion of a moral argument 'must be someone's conclusion in a sense more substantial than is suggested by the fact that he feels compelled to write it at the end of a piece of reasoning on a blackboard' (2004: 324).

Gaita points to a demand, when talking morally, to 'stand behind one's words' (2004: 324) or, as Wittgenstein formulated it, 'to speak for oneself' (Waismann 1965: 16), 'to step forth as an individual and speak in the first person' (McGuinness 1979: 117). 'Thought which issues into a mere 'blackboard conclusion', that is, a conclusion which seems inescapable when we write an argument on a blackboard, but which is a conclusion that we cannot seriously assert or even wish to assert, is thought that can have only the appearance of rigour' (Gaita 2004: 325). So what we expect from those offering moral arguments is not only that they take us into account as individuals and that they leave room for the individual moral task that comes with moral problems, but that they also speak to us with an individual voice. If they do not, we will and should not let their arguments weigh on our considerations of what we morally ought to do. Not because their arguments are likely to be logically invalid or because their conclusions are likely to be wrong (although, if someone is morally jaded, the conclusion is likely to be wrong), since we are not concerned here with ways to determine whether a given argument is logically invalid or a conclusion wrong (which should not be taken to imply that it is not crucially important to determine this!), but because they will not be moral arguments in the thick sense. If Billy seeks advice from a professor of ethics, and if this professor is clearly morally jaded, then Billy will simply think that he has lost his time. What the professor says will not weigh with him, not speak to him, and so it cannot speak for or against a way of acting. And if it cannot do that, it does not deserve to be taken into consideration as a serious response to a moral problem.

\section{An Absence of Morality}

I have discussed four ways in which morality can be absent from moral arguments in the thin sense, ways that have been offered in a Wittgensteinian tradition of moral philosophizing (but 
This is the preprint version of an article published in Argumentation 30 (4), 443-463. The final publication is available at Springer: https://link.springer.com/article/10.1007/s10503015-9389-8. Please cite the published version only.

not exclusively in this tradition). ${ }^{15}$ Even if we have no independent reason to question the truth of the premises or the logical validity of the argument, a thin moral argument will fail to give us a reason to do whatever it claims that we ought to do if

1. The argument involves or leads to the denial of a moral certainty.

2. The argument displays no participant attitude.

3. The argument offers no deepened understanding of the problem.

4. The argument denies or ignores the personal character (in three different senses) of moral problems.

The emphasis has been on giving an overview of ways in which morality can be absent from moral arguments, on bringing them together within the framework of thin and thick moral arguments, on showing relations and highlighting distinctions between them. Undoubtedly, they each deserve an article or book-length treatment that I cannot offer here, and I hope that the present article will encourage much-needed work in that direction.

In general, we can say that an absence of morality in thin arguments means that these arguments will fail to give us reason to do whatever they claim that we ought to do. The point is not so much that thin arguments are wrong. Rather, they are the wrong kind of arguments in response to people's moral problems. They pass the problem by or, put differently, do not adequately connect to the problem, and that is why we should not let them weigh upon our deliberations about what we morally ought to do. To bring that out, I have drawn upon a distinction between thin and thick moral arguments. Thickness, of course, comes in degrees, and many moral arguments are more or less thick. That is, often the participant attitude is not completely absent, some deepened understanding is offered and the personal character of moral problems has more or less been taken into account. My main point can therefore be taken as a rather modest one, since it only involves claiming that arguments in which morality is absent in one or more of the four ways mentioned do not qualify as proper responses to real-life moral problems. ${ }^{16}$

\footnotetext{
${ }^{15}$ Readers have remarked that, for example, Charles Taylor (1989) and Michael Walzer $(1987 ; 1994)$ have made points similar to those developed in this article. I fully agree, but I cannot here spell out the similarities and differences between this article and their accounts.

${ }^{16}$ The absence of morality in one of these ways will often not be a matter of course: while Glock understands Singer's argument as leading to the denial of a moral certainty, some will deny that this is so. The distinction between thin and thick arguments is not sharp, but that does not make it useless. Wittgenstein addresses the objection that 'a boundary [in our case, the boundary between thin and thick moral arguments] which is not sharply defined is not really a boundary at all' and that, consequently, we 'haven't accomplished anything at all' (2009a: §99). The vagueness of our boundary between thin and thick moral arguments is not to be denied, but it
} 
This is the preprint version of an article published in Argumentation 30 (4), 443-463. The final publication is available at Springer: https://link.springer.com/article/10.1007/s10503015-9389-8. Please cite the published version only.

One could remark that the thicker an argument is, the less general it is and the less application it has. The perfectly thick would be perfectly personal and the question is whether we can then still speak of an argument. If no degree of generality is allowed in moral arguments, then what is left for moral philosophers to do $?^{17}$ The answer to this objection is that I have not wished to claim that moral arguments should be, or aim to be, perfectly thick or perfectly personal. Some degree of generality is allowed in (and may even be necessary for) moral arguments, as long as their personal character has been taken into account. My point is not that 'the thicker a moral argument, the better', but only that a minimum of thickness is required if a moral argument is to give us reason to do whatever it claims that we ought to do. Moreover, thickness, although it has been my focus, is not the only criterion by which to judge moral arguments. The logical validity of the argument obviously plays a crucial role, too (albeit not the only crucial role, as I have wished to make clear). An argument may be sufficiently thick and logically invalid, or insufficiently thick and logically valid, and in both cases it will fail to give us reason to do whatever it claims that we ought to do. A good moral argument is both logically valid and reasonably thick. It appeals both on the argumentative and on the personal level.

The distinction between thin and thick moral arguments invites related distinctions that I have used, but not explicitly commented upon. Take, for example, the distinction between a moral issue as something that all moral arguments, thin and thick, deal with, and a moral problem as something that only thick moral arguments can properly deal with. According to this distinction, moral philosophers often deal with moral issues rather than with moral problems. A moral problem is here understood as the kind of problem people actually having the problem (people having to decide, being in the morally difficult situation) are dealing with, as a problem of life rather than a problem in philosophy. A moral issue (such as the permissibility of abortion or euthanasia) is, in this sense of 'moral problem', not a moral problem for everyone (not, for instance, for most moral philosophers writing about it), and when it is a moral problem, it will be a problem about the permissibility of abortion in a particular case. These distinctions (although, of course, not always sharp) are often ignored, which leads to distorted ('over-philosophized') views of what it is to have a moral problem

\footnotetext{
does not stand in the way of our boundary being a boundary. What it does stand in the way of is our being able to say without doubt in every conceivable case whether a moral argument is thick or merely thin. Even if this boundary is vague, that does not prevent us from showing that a certain argument falls on this or that side of it.

${ }^{17}$ I would like to thank an anonymous reviewer for pressing this objection.
}

[Type here] 
This is the preprint version of an article published in Argumentation 30 (4), 443-463. The final publication is available at Springer: https://link.springer.com/article/10.1007/s10503015-9389-8. Please cite the published version only.

and what kind of response, answer or argument such problems ask for. Such distorted views reveal themselves in what Glock diagnoses as the uncanny willingness to follow thin moral arguments wherever they lead, or in what Gaita sees as a philosophers' 'ideal of intellectual purity which takes as its exemplar someone who would turn his life upside down after stumbling across an argument' (2004: 317). The distinctions, reasons and reflections offered in this article may help to dispel the attractiveness of such ideals, for they show how to avoid confusion between moral issues and moral problems and the respective responses (thin and thick) that they require.

\section{Compliance with Ethical Standards}

Disclosure of potential conflicts of interest

The authors declare that they have no conflict of interest.

Research involving human participants and/or animals

This article does not contain any studies with human participants or animals performed by any of the authors.

\section{Informed consent}

Informed consent was obtained from all individual participants included in the study.

\section{References}

Blum, Lawrence A. 1994. Moral perception and particularity. Cambridge: Cambridge University Press.

Cavell, Stanley. 1999. The claim of reason. Wittgenstein, skepticism, morality, and tragedy. Oxford: Oxford University Press. First published in 1979.

de Waal, Frans. 2009. Primates and philosophers. How morality evolved. Princeton: Princeton University Press.

Diamond, Cora. 2002. 'What if $\mathrm{x}$ isn't the number of sheep?' Wittgenstein and thoughtexperiments in ethics. Philosophical Papers 31: 227-250.

Gaita, Raimond. 2004. Good and evil. An absolute conception. London: Routledge. Second edition. First published in 1991.

Geertz, Clifford. 1973. The interpretation of cultures. Selected essays. New York: Basic Books. 
This is the preprint version of an article published in Argumentation 30 (4), 443-463. The final publication is available at Springer: https://link.springer.com/article/10.1007/s10503015-9389-8. Please cite the published version only.

Glock, Hans-Johann. 2008. What is analytic philosophy? Cambridge: Cambridge University Press.

Hacker, P. M. S. 2009. Philosophy: a contribution not to human knowledge but to human understanding. In The nature of philosophy (Royal Institute of Philosophy Supplement 65), ed. Anthony O'Hear, 129-153. Cambridge: Cambridge University Press.

Lovibond, Sabina. 1983. Realism and imagination in ethics. Oxford: Blackwell.

McGuinness, Brian (ed). 1979. Wittgenstein and the Vienna Circle. Oxford: Blackwell.

Murdoch, Iris. 2001. The sovereignty of good. London: Routledge. First published in 1970.

Pleasants, Nigel. 2008. Wittgenstein, ethics and basic moral certainty. Inquiry 51: 241-267.

Pleasants, Nigel. 2015. If killing isn't wrong, then nothing is. A naturalistic defence of basic moral certainty. Ethical Perspectives 22: 197-215.

Rhees, Rush. 1965. Some developments in Wittgenstein's view of ethics. The Philosophical Review 74: 17-26.

Rhees, Rush. 1999. Moral questions. Basingstoke: MacMillan Press.

Rummens, Stefan. 2013. On the possibility of a Wittgensteinian account of moral certainty. The Philosophical Forum 44: 125-147.

Ryle, Gilbert. 2009. The thinking of thoughts. What is 'le Penseur' doing? In Collected papers volume 2. Collected essays 1929-1968, 494-510. London: Routledge. First published in 1968.

Singer, Peter. Speciesism and moral status. Metaphilosophy 40: 567-581.

Strawson, P. F. 2009. Freedom and resentment. In Free will, ed. Derk Pereboom, 148-171. Indianapolis: Hackett.

Taylor, Charles. 1989. Sources of the self. The making of the modern identity. Cambridge (Mass.): Harvard University Press.

Waismann, Friedrich. 1965. Notes on talks with Wittgenstein. The Philosophical Review 74: 12-16.

Walzer, Michael. 1987. Interpretation and social criticism. Cambridge (Mass.): Harvard University Press.

Walzer, Michael. 1994. Thick and thin. Moral argument at home and abroad. Notre Dame: University of Notre Dame Press.

Williams, Bernard. 1985. Ethics and the limits of philosophy. Cambridge (Mass.): Harvard University Press.

[Type here] 
This is the preprint version of an article published in Argumentation 30 (4), 443-463. The final publication is available at Springer: https://link.springer.com/article/10.1007/s10503015-9389-8. Please cite the published version only.

Wittgenstein, Ludwig. 1975. On certainty. Oxford: Blackwell.

Wittgenstein, Ludwig. 1999. Denkbewegungen: Tagebücher 1930-1932, 1936-1937.

Frankfurt am Main: Fischer Taschenbuch Verlag.

Wittgenstein, Ludwig. 2009a. Philosophical investigations. Oxford: Wiley-Blackwell.

Wittgenstein, Ludwig. 2009b. Philosophy of psychology - a fragment. In Philosophical investigations. Oxford: Wiley-Blackwell.

Wittgenstein, Ludwig. 2014. Lecture on ethics. Oxford: Wiley-Blackwell. 